Research article

\title{
Impact of in utero exposure to EtOH on corpus callosum development and paw preference in rats: protective effects of silymarin Nicol Moreland, Linda La Grange* and Rebecca Montoya
}

Address: Department of Behavioral Sciences, New Mexico Highlands University, 117 Hewett Hall, Las Vegas, NM 87701

E-mail: Nicol Moreland - nicolmoreland@hotmail.com; Linda La Grange* - lagrange_l@nmhu.edu; Rebecca Montoya - sarahnc7@hotmail.com *Corresponding author

Published: II November 2002

BMC Complementary and Alternative Medicine 2002, 2:10
Received: 18 July 2002

Accepted: II November 2002

This article is available from: http://www.biomedcentral.com/1472-6882/2/10

(C) 2002 Moreland et al; licensee BioMed Central Ltd. This article is published in Open Access: verbatim copying and redistribution of this article are permitted in all media for any purpose, provided this notice is preserved along with the article's original URL.

\begin{abstract}
Background: Using a rat model we have found that the bioflavonoid silymarin (SY) ameliorates some of the negative consequences of in utero exposure to ethanol (EtOH). In the current study our aim was to determine if laterality preference and corpus callosum development were altered in rat offspring whose mothers were provided with a concomitant administration of SY with EtOH throughout gestation.
\end{abstract}

Methods: We provided pregnant Fisher/344 rats with liquid diets containing 35\% ethanol derived calories (EDC) throughout the gestational period. A silymarin/phospholipid compound containing $29.8 \%$ silybin was co administered with $\mathrm{EtOH}$ to a separate experimental group. We tested the offspring for laterality preference at age 12 weeks. After testing the rats were sacrificed and their brains perfused for later corpus callosum extraction.

Results: We observed incomplete development of the splenium in the EtOH-only offspring. Callosal development was complete in all other treatment groups. Rats from the $\mathrm{EtOH}$-only group displayed a left paw preference; whereas control rats were evenly divided between right and left paw preference. Inexplicably both SY groups were largely right paw preferring.

Conclusions: The addition of SY to the EtOH liquid diet did confer some ameliorative effects upon the developing fetal rat brain.

\section{Background}

Fetal alcohol syndrome (FAS) children do not display the normal hemispheric dominance patterns observed in non-FAS children [1]. Dominance has been disrupted or is, in some cases, completely absent, depending on the amount of tissue loss in the corpus callosum. Morphological abnormalities, one of which is corpus callosum hypoplasia, has been observed in children with FAS [2]. Archibald et al. [3], using structural magnetic imaging
(sMRI), also noted that there were corpus callosum abnormalities in children who had experienced prenatal exposure to ethanol. In a magnetic resonance imaging (MRI) study of adult FAS males, callosal morphological data, when compared with landmark data, differed significantly from that of control males [4].

Agenesis of the corpus callosum occurs as a consequence of early embryonic insult. The exact time of the insult usu- 
ally determines the extent of commissural agenesis. Jeeves et al. [5] reported a timetable in which, if the insult occurs before the tenth embryonic week (in humans), all forebrain commissures will be absent. Miller [6] observed that in utero exposure to ethanol (EtOH) disrupted the distribution of callosal projection neurons in the rat somatosensory cortex. The complete absence of a corpus callosum in rats exposed in utero to EtOH has been documented by several studies [7-9]. Because in utero exposure to EtOH affects both corpus callosum development and laterality, researchers have turned to the rat model to assess the impact of EtOH on both measures.

In Zimmerberg et al. [10] rats prenatally exposed to a 35\% ethanol derived calories (EDC) liquid diet did not display a preferred side for the 2-hole nose-poke apparatus, unlike rats whose mothers were maintained on a chow or liquid diet. Later, Zimmerberg et al. [1] assessed laterality using a left/right lever choice on a continuous reinforcement schedule. Again the rats exposed in utero to EtOH displayed less side preference than the chow fed and liquid diet pairfed rats. When London [11] tested paw preference in rats, he found that rats exposed to ethanol during gestation were more likely than control rats to preferentially use the left paw. In 1989, Zimmerberg et al. [12] tested preferred tail direction in neonates exposed in utero to EtOH. When compared to the 0\% EDC group and the chow group, a left-preferred tail direction was exhibited by rats from the 35\% EDC group. Thus it appears that in utero exposure to ethanol, at least in rats, results in a disruption of laterality patterns.

We have investigated the potential fetoprotective capacity of silymarin (SY) against the toxic effects of in utero exposure to ethanol. Silymarin has long been noted for its hepatoprotective properties [13]. The mechanisms through which SY is thought to manifest its therapeutic effects include the following: 1) enhanced protein synthesis $[14], 2)$ scavenging free radicals [15], 3) prevention of glutathione (GSH) depletion [16], and 4) preservation of cell membrane integrity [17]. The theories formulated to explain the physiological events that culminate in fetal alcohol syndrome include decreased antioxidant levels, decreased protein synthesis, increased free radical activity, and disrupted membrane function. The observation that the protective effects of SY and the causal factors in FAS overlap, led us to investigate the possibility that SY might have application as a fetoprotectant compound. In a series of studies conducted in our lab we have demonstrated that the coadministration of SY with ethanol prevents ethanol-induced decreases in neonate mortality rate, decreases in pup birth weight, and increases in liver and brain gamma glutamyl transpeptidase (GGTP) activity $[18,19]$. SY also prevented the deficits in spatial memory and so- cial memory observed in rats exposed in utero to EtOH $[20,21]$.

Given that SY has been successful in ameliorating some of the negative consequences of in utero exposure to EtOH (in the rat model), we examined the possibility that SY might prevent EtOH-induced callosal agenesis and the disruption of laterality (as measured by paw preference).

\section{Methods \\ Subjects}

Subjects were 50 female Fisher/344 rats weighing 235$245 \mathrm{~g}$. The females were housed with male rats until pregnancy was confirmed by vaginal smear. Once pregnancy was confirmed, the rats were placed in standard plastic laboratory maternal tubs and assigned to one of five gestational treatment groups. Ten pregnant females were assigned to each treatment group. Group 1 consisted of pregnant females that received the liquid diet regimen (Bioserve; Frenchtown, NJ) containing an isocaloric amount of dextrin maltose that matched the caloric amount in the EtOH diet. Group 2 rats were provided with the liquid diet to which a $400-\mathrm{mg} / \mathrm{kg}$ dose of silymarin (SY) was added. The SY, provided by Inverni della Beffa, Milano, Italy, contained $29.8 \%$ silybin complexed with phosphatidylcholine. The dose administered to the rats was based on the percent active ingredient in the compound and was derived from data acquired in our previous studies $[18,19]$. Group 3 rats received the liquid diet, which contained both the SY and 35\% ethanol-derived calories $(6.7 \%$ EtOH solution). In previous studies we established blood alcohol concentrations (BACs) for all experimental groups and ascertained that SY does not have any appreciable affect on BAC [21]. The rats in Group 4 were maintained on the 35\% EDC liquid diet and Group 5 rats were provided with unlimited access to Purina lab chow. The amount of liquid diet provided to the rats in Groups 1, 2, and 3 was determined by the amount of liquid diet consumed the preceding day by the rats in Group 4. The liquid diet treatments were discontinued five days before the dams gave birth at which time they were provided access to Purina lab chow. When the EtOH administration is continued until birth, pup survival rats are extremely low. Once pups reached age 18-21 days they were weaned and placed in individual standard laboratory cages. On the day of weaning we randomly selected one female pup from each litter and as subjects in the laterality testing procedure. We used females in an effort to remedy the paucity of FAS-related data collected on female rodents. A total of 10 female rat pups were selected from each of the five original treatment groups. 
Table I: Weight at Birth and Weaning and Percent Weight Gain

\begin{tabular}{|c|c|c|c|c|c|}
\hline & \multicolumn{2}{|c|}{ Birth Weight (g) } & \multicolumn{2}{|c|}{ Wean Weight (g) } & \multirow[t]{2}{*}{ \% Weight Gain } \\
\hline & $M$ & SD & $M$ & SD & \\
\hline LD & 5.65 & .326 & 50.08 & 9.11 & 89 \\
\hline $\mathrm{EtOH}$ & $4.96 *$ & .721 & $34.12 * * *$ & 5.18 & 85 \\
\hline SY/EtOH & 5.66 & .730 & 47.39 & 8.09 & 88 \\
\hline SY & 5.94 & .512 & $42.66^{*}$ & 6.54 & 86 \\
\hline Chow & 6.03 & .598 & 49.18 & 9.99 & 87 \\
\hline
\end{tabular}

Note. $*=<.05 ; * *=<.01 ; * * *=<.001$. All comparisons were made to the LD group. $\mathrm{N}=10$ for each group.

\section{Apparatus and procedures}

\section{Testing apparatus for laterality}

All testing sessions took place in a reaching apparatus. The apparatus was made up of three contiguous plastic cubicles, each of which measured $24.13 \mathrm{~cm} \times 7.62 \mathrm{~cm} \times 16.41$ $\mathrm{cm}$. The adjoining walls of the cubicle were $6.35 \mathrm{~mm}$ thick and were painted white so that rats in adjacent cubicles could not see each other. An $11 \mathrm{~mm}$ tube was installed in the face of each cubicle. All test sessions were videotaped.

\section{Laterality testing procedure}

The rats began laterality testing at age 12 weeks. They were food-deprived for 14-21 hr prior to the testing sessions and each rat participated in three testing sessions. They were placed three at a time into the reaching apparatus, one in each cubicle. Rats remained in the reaching apparatus until they had either reached 50 times for food (Fruit Loops) or one hour had passed. A single Fruit Loop was placed in the reaching tube for each trial. A successful reach was defined as the rat obtaining the piece of Fruit Loop. Each time the Fruit Loop was retrieved another piece was immediately placed into the tube. Upon completion of a testing session rats were taken out of the reaching apparatus and placed back into their cage.

\section{Perfusion}

After all of the rats had completed the reaching protocol they were anesthetized and intracardially injected first with Ringers solution and then with a fixing solution. After sacrifice the brains were removed, preserved in formalin, and stored in a refrigerator for later corpus callosum extraction.

\section{Corpus callosum extraction}

Because hemisphere weights were also dependent variables a cut was made through the longitudinal fissure that separated the two hemispheres, which then exposed the two halves of the corpus callosum. The hemispheres were weighed separately prior to corpus callosum extraction. Using a surgical knife the corpus callosum was outlined and lifted away from the rest of the brain. The two halves of the corpus callosum were weighed separately on an analytical balance. The total length of the corpus callosum was measured before and after extraction. The genu, body, and splenium were identified to confirm complete development of the corpus callosum.

\section{Statistics}

The criterion for assessing individual laterality was generated from binomial $z$ scores. To identify a group of rats as demonstrating paw preference, 7 of 10 rats had to be observed reaching in the same direction. Three raters, who were unaware of treatment groupings, observed and counted the reaches. The Statistical Package for Social Sciences (SPSS) Reliability Analysis was used for inter-rater reliability. A priori contrasts were conducted to determine if differences existed between groups on all dependent measures (laterality, corpus callosum [development and weight], splenium development, total brain weight, and pup weight gain).

\section{Results}

Pup weights were recorded at birth and again when the rats were weaned. An ANOVA and subsequent post hoc Tukey comparisons revealed that there were no significant birth weight differences for any experimental group as compared with the LD group; although, the overall ANOVA was significant, $\mathrm{F}(4,45)=4.98, \mathrm{p}<.05)$. However, when the wean weights were analyzed, the ANOVA results were significant, $\mathrm{F}(4,45)=6.77, \mathrm{p}<.01$ and, the posthoc tests specified that the EtOH group $(\underline{M}=43.12 \mathrm{~g})$ differed significantly from the LD group $(\underline{M}=50.08 \mathrm{~g}), \mathrm{t}(45)=$ $4.476, \underline{p}<.001$. This indicates that the EtOH pups gained comparatively less weight during the period between postnatal day (PND) 1 and PND 20, which is when the pups were weaned. A percent weight gain was calculated for 
Table 2: Weight of Brain and Corpus Callosum and Brain:CC Ratio

\begin{tabular}{|c|c|c|c|c|c|}
\hline & \multicolumn{2}{|c|}{ Brain Weight (g) } & \multicolumn{2}{|c|}{ CC Weight (g) } & \multirow[t]{2}{*}{ Ratio Brain:CC } \\
\hline & $M$ & SD & $M$ & SD & \\
\hline LD & 1.937 & .066 & .001409 & .0015 & $\mathrm{I}: 137$ \\
\hline $\mathrm{EtOH}$ & 1.304 & .135 & $.000802 * * *$ & .0005 & $1: 162$ \\
\hline SY/EtOH & 1.945 & .117 & $.001267 * *$ & .0012 & $1: 152$ \\
\hline SY & 1.899 & .182 & $.001277^{*}$ & .0015 & $\mathrm{I}: 148$ \\
\hline Chow & 1.378 & .043 & $.000985 * * *$ & .0009 & $1: 139$ \\
\hline
\end{tabular}

Note. $*=<.05 ; * *=<.01 ; * * *=<.001$. All comparisons were made to the LD group. $N=10$ for each group.

each group (see Table 1). Eta square was calculated and indicated that $61 \%$ of the variance in pup weight gain values was attributable to the treatment received during gestation.

Total brain weight and corpus callosum weight were determined for each of the pups and a total weight to corpus callosum ratio calculated (see Table 2). Eta square was again calculated for the variance in corpus callosum weight resulting in $56 \%$ of the variance attributable to the treatment condition. After perfusion the brains were visually inspected to determine whether or not the splenium was fully developed. Of the 50 rats tested, $8 \mathrm{did}$ not have a fully developed splenium. All 8 rats were from the EtOH group (see Table 3). A priori contrasts were conducted to assess group differences. All of the group comparisons were made with the Liquid Diet (LD) group. Significant differences are reported in Tables 1,2,3.

\section{Discussion}

EtOH had an adverse impact on birth weight as indicated in Table 1. Further, the in utero exposure to EtOH also prevented normal weight gain during the 20-day suckling period. SY given in combination with EtOH appeared to prevent the EtOH-associated low birth weight and attenuated weight gain. Although the birth weight of the SY-only pups was normal, weight gain during the suckling period was significantly less than that of the LD group. Weight gain for the SY pups, however, was still more than that observed for the EtOH pups. In a previous study [20] SY pup weight gain did not differ significantly from weight gained by LD pups.

Brain weights did not differ significantly, although the lowest weights were observed in the EtOH. Corpus callosum (CC) weights did vary significantly, for which the EtOH pups had the lowest weights. Inexplicably, the Chow pup callosal data weight data did not differ from that of the EtOH pups. However, when the ratio of brain weight to $\mathrm{CC}$ weight was calculated there were no significant group differences. The $\mathrm{EtOH}$ group brain to $\mathrm{CC}$ weight ratio indicated that the $\mathrm{CC}$ weight as compared to total brain weight was the lowest observed among all of the treatment groups. This lower CC weight might be associated with the unusual left paw preference displayed by the EtOH pups. As an indication of EtOH and SY fetal effects the CC weight measure does not seem to provide much relevant information, whereas the measure of splenium development clearly indicates EtOH-induced disruption. The in utero effect of EtOH on splenium development has also been observed in humans with FAS. Sowell et al. [22], using MRI analytic methods determined that EtOH-related callosal area reductions were most severe in the splenium.

Consistent with the London [11] investigation, the EtOHexposed rats displayed a left paw preference. Further evidence of laterality disruption was manifested by incomplete splenium development in 8 of the $10 \mathrm{EtOH}$-exposed rats. The paw preference scores in the LD and Chow groups indicated an even distribution between left and right paw preference. An unexpected finding was that of the strong right paw preference displayed by the rats from the SY and SY/EtOH groups. Given the 50:50 left/right paw preference of the Chow and LD groups; the expected outcome of SY influence would be the preservation of the 50:50 ratio. The SY paw preference results are, however, consistent with a very recent study by Pence [23]. Male and female rats were tested for paw preference using a food-reaching task. There was no significant sex difference. He did observe that $70.2 \%$ of the rats were right pawed, 19.3\% were left pawed, and $11.9 \%$ were ambidextrous. Our observations can be summarized as follows: 1) Fisher/344 rats when not subject to any form of prenatal insult and subsequently raised with adequate nutrition and housing do not, as a group, display any particular paw 
Table 3: Splenium Development and Paw Preference

\begin{tabular}{|c|c|c|c|c|c|}
\hline & \multicolumn{2}{|c|}{ Splenium } & \multicolumn{3}{|c|}{ Incomplete Splenium } \\
\hline & Left & Right & Left & Right & Total \\
\hline LD & 5 & 5 & & & 10 \\
\hline $\mathrm{EtOH}$ & I & 1 & 6 & 2 & 10 \\
\hline $\mathrm{SY} / \mathrm{EtOH}$ & I & 9 & & & 10 \\
\hline SY & I & 9 & & & 10 \\
\hline Chow & 6 & 4 & & & 10 \\
\hline Total & 14 & 28 & 6 & 2 & 50 \\
\hline
\end{tabular}

preference. 2) Rats when exposed in utero to EtOH experience tissue loss in the splenium and, as a group, display a left paw preference. 3) Rats that have been exposed in utero to EtOH co-administered with SY have a fully intact corpus callosum, yet display a right-paw preference. Why SY would have any impact on laterality that is distinct from EtOH exposure is puzzling. There is a possible explanation in light of the gender-specific differences observed in callosal size [24] coupled with the fact that prenatal exposure to EtOH causes feminization of male rats and defeminization of female rats $[12,25,26]$. There is a hormonal influence on the developing commissural pathway that could be disrupted by a number of EtOH-induced aberrations in hormone activity, such as the diminished perinatal surge of testosterone observed in EtOH-exposed male fetal rats [27]. The EtOH-induced attenuation of the testosterone surge eliminated the normal sex difference in rat callosal size. In a previous study we observed that the coadministration of SY with EtOH to pregnant dams prevented the EtOH-induced deficits in social recognition observed in the EtOH-exposed offspring [20]. Social memory in rats is a sexually dimorphic behavior that requires adequate levels of perinatal and neonatal androgen activity. In utero exposure to EtOH reduces testosterone levels as well as maternal levels of estrogen; consequently there is a reduction in P450-aromatase activity $[28,29]$. This then results in a reduction in estrogen and estrogen receptor activation. Estrogen receptor activity is necessary for the expression of androgen-driven behavior in rodents [30,27]. In addition to behavior, estrogen also affects neurogenesis, synaptogenesis, and synaptic modifications [31]. Our subjects were the female offspring of the various treatment groups. As previously confirmed [32], the rat's corpus callosum (CC) is a sexually dimorphic structure with the larger $\mathrm{CC}$ observed in male rats. Fitch and colleagues [32] also determined that the femini- zation (reduction in size as compared to the CC of male rats) of the female $\mathrm{CC}$ only occurs if the ovaries are intact and the CC is exposed to estrogen. Recently, Bimonte et al. [33] established that neonatal exposure to estrogen is essential to feminine-specific brain organization to the extent that the brain can respond appropriately to the organizing effects of subsequent estrogen exposure. Experimental rats were administered an estrogen receptor blocker, and later at postnatal day 70 these rats responded to estrogen administration with an increase in CC size; an effect opposite of what would be expected. Dehmlow et al. [17] have established that silymarin can compete with estradiol at estradiol receptor binding sites [17]. Therefore, it is possible that the ameliorative effects of SY observed in the present study can be attributed to estrogen receptor activation at developmentally appropriate times.

\section{Conclusions}

Because callosal development was complete in rats exposed to the co-administration of SY with EtOH, it appears that SY conferred some ameliorative effects upon the corpus callosum developmental process. Without the SY, EtOH-exposed pups clearly displayed EtOH-induced disruption to normal callosal development. Even though the mechanism for the protective action of SY is not clearly understood, our consistent findings of fetoprotectivity in the presence of in utero EtOH exposure merit further exploration.

\section{Competing interests}

None declared

\section{Author's contributions}

Author 1 NM performed all of the neuroanatomical assessments in the study and participated in the design of the study. 
Author 2 LL Participated in the design of the study, the statistical analysis, and drafted the manuscript.

Author 3 RM maintained the experimental protocol throughout the experiment and performed a portion of the laterality assessments.

\section{Acknowledgements}

This research was funded by NIH grant \#R2 IAAI I 90I-0I.

\section{References}

I. Zimmerberg B, Riley EP: Prenatal alcohol exposure alters behavioral laterality of adult offspring in rats. Alcohol Clin Exp Res I 988, I 2:259-263

2. Riikonen R, Salonen I, Partaneu K, Verho S: Brain perfusion SPECT and MRI in foetal alcohol syndrome. Dev Med Child Neurol 1999, 41:652-659

3. Archibald SL, Fennema-Notestine C, Gamst A, Riley EP, Mattson SN, Jernigan TL: Brain dysmorphology in individuals with severe prenatal alcohol exposure. Dev Med Child Neurol 200I, 43:I48154

4. Bookstein FL, Sampson PD, Streissguth AP, Connor PD: Geometric morphometries of corpus callosum and subcortical structures in the fetal-alcohol-affected brain. Teratol 200I, 64:4-32

5. Jeeves MA, Simpson DA, Geffen G: Functional consequences of transcallosal removal of intraventricular tumor. J Neurol Neurosurg Psychiatry 1979, 42:134-I42

6. Miller MW: Effects of prenatal exposure to ethanol on callosal projective neurons in rat somatosensory cortex. Brain Res 1997, 766:121-128

7. Mattson SN, Jernigen TL, Riley EP: MRI and prenatal alcohol exposure. Alcohol Health Res World 1994, 18:49-52

8. Coulter CL, Leech RW, Schaefer GB, Scheithauer BW, Brumback RA: Midline cerebral dysgenesis, dysfunction of the hypothalamic-pituitary axis, and fetal alcohol effects. Arch Neurol 1993, 50:77I-775

9. Jeret JS, Serur D, Wisniewski KE, Lubin RA: Clinicopathological findings associated with agenesis of the corpus callosum. Brain Dev 1987, 9:255-264

10. Zimmerberg B, Riley EP: Side preference behavior in rats exposed to alcohol prenatally. Neurobehav Toxicol Teratol 1986, 8:631-635

II. London W: Cerebral laterality and the study of alcoholism. Alcohol 1987, 4:207-208

12. Zimmerberg B, Reuter JM: Sexually dimorphic behavioral and brain asymmetries in neonatal rats: effects of prenatal alcohol exposure. Brain Res Dev Brain Res 1989, 46:28I-290

13. Flora K, Hahn M, Rosen H, Benner K: Milk thistle (Silybum marianum) for the therapy of liver disease. Am Gastroenterol 1998, 93:139-143

14. Sonnenbichler J, Zetle I: Plant Flavonoids in Biology and Medicine II: Biochemical, Cellular, and Medicinal Properties. (Edited by: Alan R Liss) New York 1999, 369-374

I5. Locher R, Suter PM, Weyhenmeyer R, Vetter W: Inhibitory action of silibinin on low density lipoprotein oxidation. Arzneimittelforschung 1997, 48:236-239

16. Valenzuela A, Lagos C, Schmidt K, Videla L: Silymarin protection against hepatic peroxidation induced by acute ethanol intoxication in the rat. Biochem Pharmacol 1985, 34:2209-2212

17. Dehmlow C, Erhard J, de Groot H: Inhibition of Kupffer cell functions as an explanation for hepatoprotective properties of silibinin. Hepatology 1996, 22:749-754

18. Edwards J, La Grange L, Wang M, Reyes E: Fetoprotectivity of the flavanolignan compound Siliphos against ethanol-induced toxicity. Phytother Res 2000, 14:517-521

19. La Grange L, Wang M, Watkins R, Ortiz D, Sanchez ME, Konst J, Lee $C$, Reyes E: Protective effects of the flavonoid mixture silymarin on fetal rat brain and liver. J Ethnopharm 1999, 65:53-6I

20. Busby A, La Grange L, Edwards J, King J: The use of a silymarin/ phospholipid compound as a fetoprotectant from ethanol-induced behavioral deficits. J Herbal Pharmacother 2002, 2:39-47

21. Reid C, Edwards J, Wang M, Manybeads Y, Mike L, Martinez N, La Grange L, Reyes E: Prevention by a silymarin/phospholipid compound of ethanol-induced social learning deficits in rats. Planta Med 1999, 65:421-424

22. Sowell E, Mattson S, Thompson P, Jemigan T, Riley E, Toga A: Mapping callosal morphology and cognitive correlates: effects of heavy prenatal alcohol exposure. Neurology 200I, 57:235-244

23. Pence S: Paw preference in rats. J Basic Clin Physiol Pharmacol 2002 I 3:4 |-49

24. Zimmerberg B, Mickus L: Sex differences in corpus callosum: influence of prenatal alcohol exposure and maternal under nutrition. Brain Res 1990, 537:1 I5-222

25. Handa RJ, McGivern RF, Noble ES, Gorski RA: Exposure to alcohol in utero alters adult pattern of luteinizing hormone secretion in male and female rats. Life Sci 1985, 37:1683-1690

26. Weinberg J, Clendenning S: Adrenocortical activity in females consuming alcohol during pregnancy. Alcohol Clin Exp Res 1984, 8: 126

27. McGivern RF, Raum WJ, Salido E, Redei E: Lack of preinatal testosterone surge in fetal rats exposed to alcohol : alterations in testicular morphology and physiology. Alcohol Clin Exp Res 1988, 1 2:243-247

28. Dahlgren J, Matuszczyk J, Hard E: Sexual orientation in male rats prenatally exposed to ethanol. Neurotoxicol Teratol I 99।, I 3:267269

29. Halmesmäki E, Autti I, Granström M-L, Stenman U-H, Ylikorkala O: Estradiol, estriol, progesterone, prolactin, and human chorionic gonadotropin in pregnant women with alcohol abuse. Clin Endocrinol Metab 1987, 64: I53-156

30. Roselli C, Klosterman S: Sexual differentiation of aromatase activity in the rat brain: effects of perinatal steroid exposure. Endocrinology 1998, I39:3193-3201

31. Naftolin F, Garcia-Segura LM, Keefe D, Levanth C, MacLusky NJ, Brown JR: Estrogen effects on the synaptology and neural membranes of the rat hypothalamic arcuate nucleus. Biol Reprod 1990, 42:21-28

32. Fitch RH, Cowell PE, Schrott LM, Denenberg VH: Corpus callosum: ovarian hormones and feminization. Brain Res 1991, 542:313-317

33. Bimonte HA, Fitch RH, Denenberg VH: Neonatal estrogen blockade prevents normal callosal responsiveness to estradiol in adulthood. Brain Res Dev Brain Res 2000, 30:|49-I 55

\section{Pre-publication history}

The pre-publication history for this paper can be accessed here:

http://www.biomedcentral.com/1472-6882/2/10/prepub

Publish with BioMed Central and every scientist can read your work free of charge

"BioMedcentral will be the most significant development for disseminating the results of biomedical research in our lifetime."

Paul Nurse, Director-General, Imperial Cancer Research Fund

Publish with BMC and your research papers will be:

- available free of charge to the entire biomedical community

- peer reviewed and published immediately upon acceptance

- cited in PubMed and archived on PubMed Central

- yours - you keep the copyright

Submit your manuscript here:

http://www.biomedcentral.com/manuscript/ editorial@biomedcentral.com
BioMedcentral.com 